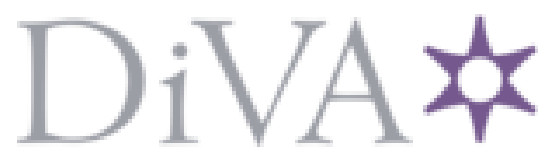

http://www.diva-portal.org

\title{
Preprint
}

This is the submitted version of a paper published in Dialectica.

Citation for the original published paper (version of record):

Åkerman, J. (2013)

Forced-March Sorites Arguments and Linguistic Competence.

Dialectica, 67(4): 403-426

http://dx.doi.org/10.1111/1746-8361.12038

Access to the published version may require subscription.

N.B. When citing this work, cite the original published paper.

Permanent link to this version:

http://urn.kb.se/resolve?urn=urn:nbn:se:su:diva- 102261 


\section{Forced-march Sorites arguments and linguistic competence}

Proponents of views according to which the extensions of vague predicates are relative to the judgemental dispositions of particular competent agents often appeal to so-called 'forced-march Sorites' experiments in order to support their theories. The most simple and direct versions of such 'forced-march Sorites arguments' are problematic, as they rest on assumptions about the connection between use and extension that opponents of agent relativists deny. This paper focuses on the idea that we could get around this problem by invoking a certain constraint on linguistic competence that lends independent support to these assumptions. It will be argued that this idea does not hold to scrutiny, and that forced-march Sorites arguments thus remain inconclusive.

\section{Preamble}

Roughly, agent relativism about vague predicates (henceforth 'agent relativism') is the view that the extensions of vague predicates are relative to the judgemental dispositions of particular competent agents. This is a view that has become increasingly popular in recent years, although it remains controversial. ${ }^{1}$

Proponents of agent relativism often try to argue for their views by appeal to so-called 'forced-march Sorites' experiments (to be further described below). ${ }^{2}$ As we shall see, the most simple and direct versions of such 'forcedmarch Sorites arguments' are at best incomplete and at worst question begging, as they rely on assumptions that opponents of agent relativism deny. In order to give any real support to agent relativism, they need to be complemented by independently supported principles that can establish the right kind of connection between use and extensions.

In what follows, we shall focus on the idea that this can be done by appeal to a certain constraint on linguistic competence, which in turn is closely related to the more general idea behind forced-march arguments, viz. that only agent relativism can make sense of the data from forced-march Sorites experiments. It will be argued below (section IV) that this idea does not hold to scrutiny, and that forced-march Sorites arguments thus remain inconclusive. But before

\footnotetext{
${ }^{1}$ References to the relevant literature will be given below, during the course of the more detailed presentation of this view.

2 The term 'forced-march Sorites' is due to Horgan (1994).
} 
This is the pre-peer reviewed version of the following article: Akerman, J. 'Forced-march Sorites arguments and linguistic competence', dialectica 67 (2013): 403-426, which bas been published in final form at bttp://dx.doi.org/10.1111/1746-8361.12038. This article may be used for non-commercial purposes in accordance with Wiley Terms and Conditions for Self-Archiving.

we turn to this matter, a more detailed presentation will be given of agent relativism (section II) and forced-march Sorites arguments (section III).

\section{Agent relativism}

Agent relativists hold that for any vague predicate ' $\mathrm{P}$ ' and any object $x$, whether or not $x$ falls in the extension of ' $\mathrm{P}$ ' at a time $t$ depends on the judgemental dispositions of a particular competent agent at $t$. This means that from the agent-relativist point of view, a proper understanding of vague predicates requires that we relativize their extensions to particular agents and times. Laurence Goldstein, a recent proponent of agent relativism, puts the idea as follows:

[T]o ask 'What is the snapping point, simpliciter, for unrelenting noise at 80 decibels?' would be nonsense. And similarly, it is nonsense - a category mistake-to ask where the red/non-red borderline is, not for a particular agent but objectively. The same can, of course, be said about the heap/non-heap borderline, the infant/non-infant borderline, the wealthy/non-wealthy borderline etc.: no such objective borderlines exist. ${ }^{3}$

What is being claimed in this passage is not that we cannot make sense of vague predicates having extensions at all, but merely that we cannot make sense of vague predicates having extensions that are not relativized to particular agents and times. Just as it does make sense to ask for the point at which a particular agent at a particular time will snap if exposed to unrelenting noise at 80 decibels, it does make sense to ask for the borderline of the extension of any vague predicate ' $\mathrm{P}$ ' relative to a particular agent at a particular time. Consider a Sorites series for 'P', i.e. a series ranging from items that are clearly $\mathrm{P}$ to items that are clearly non-P, and such that adjacent members of the series are very similar (perhaps even indiscriminable) with respect to the dimension of comparison relevant to ' $\mathrm{P}$ ' (e.g. colour if $\mathrm{P}=$ red, or number and arrangement of hair on the head if $\mathrm{P}=$ bald). For any time $t$ and agent $\mathrm{A}$ there is a point in the series at which $\mathrm{A}$ would (be disposed to) switch from an 'P'verdict to a non-' $\mathrm{P}$ '-verdict, and according to agent relativism, that point marks a (non-objective) borderline for 'P' relative to $\mathrm{A}$ and t. ${ }^{4}$ Since the switching

${ }^{3}$ L. Goldstein, 'The Sorites is nonsense disguised by a fallacy', Analysis 72 (2012), pp. 61-65, at p. 63.

${ }^{4}$ Cf. Goldstein, op. cit., at pp. 61-63. 
This is the pre-peer reviewed version of the following article: Akerman, J. 'Forced-march Sorites arguments and linguistic competence', dialectica 67 (2013): 403-426, which bas been published in final form at bttp://dx.doi.org/10.1111/1746-8361.12038. This article may be used for non-commercial purposes in accordance with Wiley Terms and Conditions for Self-Archiving.

point for a specific agent may shift over time, and since the switching point at a specific time may be different for different agents, the extension(s) of any vague predicate ' $\mathrm{P}$ ' may vary across agent and times, and should thus be relativized to particular agents and times; the extension(s) of ' $\mathrm{P}$ ' are "subjective" rather than "objective".

So, on the agent relativist picture, there is a very intimate link between the extensions of vague predicates and the way that competent speakers use them. Let us take a closer look at how one may conceive of this link. According to Diana Raffman, the extensions of vague predicates are determined by certain aspects of the agent's psychology, namely her judgemental dispositions. Such dispositions constitute what she calls "psychological" or "internal" contexts, and the relation between such dispositions and the extension(s) of a vague predicate ' $\mathrm{P}$ ' is simply that, relative to an agent $\mathrm{A}$ an object $\mathrm{O}$ falls in the extension of ' $\mathrm{P}$ ' at $\mathrm{t}$, if and only if $\mathrm{A}$ is disposed to apply ' $\mathrm{P}$ ' to o at $\mathrm{t}^{5}$

On Raffman's view, then, the psychological context co-determines the agent's actual judgement and the semantic status of the item judged. In contrast, on the agent-relativist views defended by Scott Soames and Stewart Shapiro, the judgemental dispositions determine the semantic status of the item judged indirectly, via the actual (public) judgement. ${ }^{6}$ This is but one of many interesting differences among the agent relativist theories on the market, but for present purposes we need not go further into this matter. The crucial point is that all of these theories take there to be an intimate link between the extensions of vague predicates and the way that competent speakers use them; they all comprise the thesis that vague predicates are judgement dependent in a way that guarantees that ordinary competent speakers' actual applications of vague predicates do not diverge from their extensions. ${ }^{7}$

That ' $\mathrm{P}$ ' is judgement dependent is not supposed to entail that the agent has complete access to and control over the extensions with which they use 'P'. First, the conditions in which the judgements are made may be less than

5 D. Raffman, 'Vagueness without paradox', Philosophical Review 103 (1994), pp. 41-74, at pp. 69-70, and 'Vagueness and context relativity', Philosophical Studies 81 (1996), pp. 175-192, at p. 182. In fact, her view as developed in the 1996 paper is a bit more complicated, but as argued in ******, it seems that the simpler version of Raffman's view is the most plausible one. ${ }^{6}$ S. Soames, Understanding Truth, Oxford, Oxford University Press (1999); S. Shapiro, Vagueness in Context, Oxford, Oxford University Press (2006). It is interesting to note that although Shapiro (pp. 26-27) focuses on more communal aspects of language use, he takes Raffman's account to be "more basic," as the collective judgements in Shapiro's conversational version of the forced-march Sorites are determined by the individual judgements of the conversationalists.

${ }^{7}$ One could also use the term 'response dependence' to refer to this idea. Cf. Goldstein, op. cit., at p. 63. See ****** for a more detailed discussion of different versions of judgement dependence. 
This is the pre-peer reviewed version of the following article: Akerman, J. 'Forced-march Sorites arguments and linguistic competence', dialectica 67 (2013): 403-426, which bas been published in final form at bttp://dx.doi.org/10.1111/1746-8361.12038. This article may be used for non-commercial purposes in accordance with Wiley Terms and Conditions for Self-Archiving.

optimal. For instance, the lighting conditions may be abnormal, the agent's classificatory abilities may be temporarily substandard, or the agent may be misinformed about relevant facts about the subject matter or about what comparison class is operative. Second, even when the conditions are ideal, extensions are likely to shift quite often, as the relevant dispositions may shift whenever the agent shifts her attention from one item to another. The agent will typically not be aware of such subtle shifts, and much less be able to track them. Third, Raffman suggests, plausibly enough, that the competent speakers are never disposed to judge two adjacent items differently at the moment when she is considering them simultaneously as a pair. This makes the switching point (i.e. the non-objective borderline) elusive in the sense that if the agent was previously disposed to switch between two items, the very considering of them as a pair will trigger a shift to the effect that the switching point is not there anymore. ${ }^{8}$ Fourth, since the agent cannot predict the dispositional shifts, she can never know the switching point in advance. At any time t, she is ignorant of the boundary's location at t.

The first of these points shows that although there is a sense in which judgement dependence entails that competent agents are infallible, the infallibility is, as Raffman puts it, "highly circumscribed." After all, normal competent speakers make all sorts of mistakes in their daily application of the predicates of their own language, and sometimes they even (genuinely) contradict themselves. On a charitable understanding of agent relativism, there should be room for mistakes on the part of competent speakers due to unfavourable external circumstances, misinformation, or (temporary) dips in the agent's level of performance. Let us refer to conditions in which such sources of error have been eliminated as 'optimal conditions'. For present purposes, then, the judgement-dependence thesis may be formulated as follows:

(JD) If 'P' is a vague predicate, then, provided that the conditions are optimal, the judgemental dispositions of an ordinary competent speaker $S$ determine the extensions of ' $\mathrm{P}$ ' in a way that guarantees that if $S$ applies 'P' to $x$ at $t$, then $x$ falls in the extension of 'P' (as used by $S$ at $t$ ).

\footnotetext{
${ }^{8}$ Raffman, 'Vagueness and context relativity', at p. 178. It has been argued, for instance in D.G. Fara, 'Shifting sands: an interest-relative theory of vagueness', Philosophical Topics 28 (2000), pp. 45-81, at pp. 70-71, that this feature puts agent relativists in a particularly good position to explain the appeal of soritical reasoning. See $* * * * * *$ for further discussion.

9 'Vagueness without paradox', at pp. 70-71.
} 
This is the pre-peer reviewed version of the following article: Akerman, J. 'Forced-march Sorites arguments and linguistic competence', dialectica 67 (2013): 403-426, which bas been published in final form at bttp://dx.doi.org/10.1111/1746-8361.12038. This article may be used for non-commercial purposes in accordance with Wiley Terms and Conditions for Self-Archiving.

What (JD) says is that an ordinary competent speaker's actual application of 'P' at a time $t$ cannot diverge from the extension with which $S$ uses 'P' at $t$, as long as the conditions are optimal. Of course, on the agent-relativist view, the extension here is "subjective" rather than "objective"; hence the relativization to $S$.

The idea that vague predicates are agent relative has become increasingly popular during the last couple of decades, most notably through its central role in various contextualist theories of vagueness. ${ }^{10}$ But although this idea is part and parcel of (standard) contextualism about vagueness, one need not endorse a view of this kind in order to accept agent relativism. For instance, Goldstein agrees with (standard) contextualists that vague predicates are agent relative, but he is bound to disagree with their claim that vagueness consists in a form of context sensitivity since he takes vagueness to remain even when all contextual factors are held fixed. He illustrates this point with a science fiction scenario in which a subject is presented, at time $t_{1}$, with the first item in the Sorites series and, after giving his or her verdict on it "is transported back to $t_{1}$ when the subject's brain reconfigures to the exact state, $b_{1}$, it was in at that time." "This procedure is then repeated for each of the items in the series. Goldstein maintains that although all contextual variation is eliminated in this scenario, vagueness is preserved. Thus he takes sides with those critics of contextualism about vagueness who have argued that even if vague predicates are sensitive to various contextual factors, vagueness is distinct from context sensitivity, since vagueness remains when the context is held fixed or the effects of the contextual factors are blocked. ${ }^{12}$

The fact that Goldstein's approach is (irreconcilably) different from standard contextualism about vagueness illustrates that different versions of the general agent-relativist idea can be invoked in various ways, as part of different approaches to vagueness. ${ }^{13}$ For present purposes, however, we need not go into further detail about the differences between the various contextualist theories on the market ${ }^{14}$ or about the extent to which Goldstein's theory differs from these.

\footnotetext{
${ }^{10}$ For a critical survey, see $* * * * * *$ and $* * * * * *$.

${ }^{11}$ Goldstein, op. cit., at p. 61.

12 For objections of this kind, see T. Williamson, Vagueness, London and New York, Routledge (1994), at p. 215; R. Keefe, Theories of Vagueness, Cambridge, Cambridge University Press (2000), at p. 10; J. Stanley, 'Context, interest relativity and the sorites', Analysis 63 (2003), pp. 269-280; R. Heck, 'Semantic accounts of vagueness', in Jc Beall (ed.) Liars and Heaps, New York, Oxford University Press (2003), pp. 106-127, at p. 120. See ******, ****** and ****** for detailed discussion of these objections.

13 Thanks to ****** for pointing out the need to clarify this.

${ }^{14}$ I have done this elsewhere. See $* * * * * *$.
} 
This is the pre-peer reviewed version of the following article: Akerman, J. 'Forced-march Sorites arguments and linguistic competence', dialectica 67 (2013): 403-426, which bas been published in final form at bttp://dx.doi.org/10.1111/1746-8361.12038. This article may be used for non-commercial purposes in accordance with Wiley Terms and Conditions for Self-Archiving.

\section{Forced-march Sorites arguments}

In presenting and arguing for their views, agent relativists typically appeal to an experiment of a certain kind, which has become known as the 'forced-march Sorites'. It is often conducted as a thought experiment set up in something like the following way. ${ }^{15} \mathrm{We}$ are asked to consider what would happen if an agent - a competent speaker of English - were to be led through a Sorites series of the kind described above, and forced to make a judgement of the form ' $x$ is $\mathrm{P}$ ' or ' $x$ is not $\mathrm{P}$ ', for each $x$ in the series. ${ }^{16}$ It is then assumed that the agent would, at some point during the march, switch from ' $x$ is $\mathrm{P}$ ' to ' $x$ is not P'. Moreover, it is assumed that if we were to let her do several runs through the series, starting in different places and going in different directions, the switch would occur at different points (although it would always occur outside of the range of clearly $\mathrm{P}$ items and clearly non-P items). In these thought experiments, the outputs consist in what seem to be the most plausible assumptions about how the agent would behave in the scenario described. But of course, the forced-march Sorites may also be conducted as an empirical experiment, and to the extent that this has been done, the results appear to support the outputs of the thought experiments. ${ }^{17}$

The purpose here is not to question any of these assumptions, so presently we need not worry about how solid these results are, or whether or not the assumptions of the thought experiments are correct. We can safely assume that they are sufficiently grounded, empirically or otherwise, and thus treat them as confirmed facts. Accordingly, they will henceforth be referred to as results or data rather than as assumptions.

The results of the forced-march Sorites experiment show that competent speakers' actual applications of vague predicates vary across speakers as well as over time, even when familiar contextual factors such as comparison class are held fixed. ${ }^{18}$ Let us now turn to the question of how such results can be invoked in order to argue for agent relativism.

15 For instance, see Goldstein's sci-fi version above, or Raffman's early papers on contextualism about vagueness ('Vagueness without paradox' and 'Vagueness and context relativity'.)

${ }^{16}$ Of course, one could allow a wider range of responses, but in order not to complicate matters more than necessary, let us follow Raffman ('Vagueness without paradox', at pp. 4546; 'Vagueness and context-relativity, at p. 177) in restricting ourselves to experiments in which only two forms of judgements are allowed. The judgement ' $x$ is not red' may also be taken to cover all forms of "non-red" verdicts, including gap- and glut-judgements (cf. Goldstein, op. cit., at p. 61).

${ }^{17}$ See D. Raffman, Unruly Words: A Study of Vagueness. Oxford University Press (forthcoming).

18 It will be assumed throughout that the variations cannot be explained in terms of uncontroversial forms of context sensitivity. This is something on which both proponents and critics of contextualism and agent relativism agree. 
This is the pre-peer reviewed version of the following article: Akerman, J. 'Forced-march Sorites arguments and linguistic competence', dialectica 67 (2013): 403-426, which bas been published in final form at bttp://dx.doi.org/10.1111/1746-8361.12038. This article may be used for non-commercial purposes in accordance with Wiley Terms and Conditions for Self-Archiving.

Consider the following simple forced-march Sorites argument. Given that different competent speakers in a linguistic community judge the items in the middle of the series differently (even under optimal conditions), and that one and the same speaker judges the same items differently on different occasions, there cannot be any shared or stable extension for ' $\mathrm{P}$ ' in this community. This is what might be called a 'direct' forced-march Sorites argument. It starts from the forced-march data-which show that there are certain variations across competent speakers and over time when it comes to how vague predicates are actually applied - and then proceeds directly to the claim that the extensions of these predicates must vary in the same way, which in turn yields the conclusion that there cannot be any objective, shared extension for ' $\mathrm{P}$ '. ${ }^{19}$

In order to see clearly what the problem with this argument is, it will be helpful to observe a very basic distinction between the use of a predicate and the extension with which the predicate is used. In the simple cases that we are concerned with here, to use a predicate ' $P$ ' is to make judgements of the form ' $x$ is $\mathrm{P}$ ' and ' $x$ is not $\mathrm{P}$ ' with respect to a certain range of objects, while the extension with which 'P' is used by a speaker $S$ at a time $t$ is the set of objects of which 'P' is true (relative to $S$ and $t$ ). Now, the crucial move in direct forcedmarch arguments can be seen to rely on the following claim concerning the connection between use and extension:

(i) If two competent speakers $S$ and $S$ ' use 'P' differently with respect to one and the same range of objects $R$ (under optimal conditions), then $S$ and $S$ ' use 'P' with different extensions (at the respective times of judgement), and

(ii) If a competent speaker $S$ uses 'P' differently with respect to $R$ at $t$ and $t$ ' (under optimal conditions), then $S$ uses 'P' with different extensions at $t$ and $t$ '.

Unless we accept (UE), we have no reason to accept that competent speakers use ' $\mathrm{P}$ ' with different extensions merely on the basis of the observation that they judge certain items in the Sorites series differently (i.e. apply 'P' differently to one and the same range of objects).

Now, if one is already a convinced agent relativist, one is not likely to find anything problematic about accepting (UE). Indeed, given (JD), competent agents' actual applications of 'P' (under optimal conditions) cannot diverge from the extensions with which they use 'P', and thus any difference in actual application entails a corresponding difference in extension; if $S$ judges $x$ to be

19 This is, in effect, how Goldstein argues for agent relativism (op. cit., at pp. 62-64). 
This is the pre-peer reviewed version of the following article: Akerman, J. 'Forced-march Sorites arguments and linguistic competence', dialectica 67 (2013): 403-426, which bas been published in final form at bttp://dx.doi.org/10.1111/1746-8361.12038. This article may be used for non-commercial purposes in accordance with Wiley Terms and Conditions for Self-Archiving.

$\mathrm{P}$ at $t$, then the extension with which $S$ uses ' $\mathrm{P}$ ' at $t$ must include $x$, and if $S$ ' judges that $x$ is not $\mathrm{P}$ at $t$, then the extension with which $S$ ' uses ' $\mathrm{P}$ ' at $t$ cannot include $x$. It follows that if two competent speakers $S$ and $S$ ' (or one and the same competent speaker at two different times) apply 'P' differently to one and the same (range of) object(s) (under optimal conditions), then they thereby use 'P' with different extensions (at the respective times of judgement).

However, an objectivist ${ }^{20}$ will conceive matters quite differently, since on her view, the extensions with which competent speakers use 'P' are not taken to be determined in accordance with (JD). Thus, she will want to allow that, even under optimal conditions, two competent speakers $S$ and $S$ ' can use 'P' with the same extension even if they apply it differently, and that one and the same competent speaker $S$ can use 'P' with the same extension at $t$ and $t$ ' even if $S$ applies 'P' differently at $t$ and $t$ '. In other words, an objectivist will deny (UE).

To simply assume that (UE) is correct would thus amount to begging the question against the objectivist. Clearly then, in order to turn a direct forcedmarch Sorites argument into a convincing argument, (UE) must be given additional, independent support. At this point, it is natural to turn to what has seemed to be the general driving idea behind forced-march Sorites arguments, namely the idea that making sense of the forced-march data requires that we adopt principles like (JD) and (UE). ${ }^{21}$

Here is how such an argument would go. If we were to follow the objectivist in denying these principles, then we would have to ascribe certain (semantic) mistakes to the agent in the forced-march Sorites, even when the conditions are optimal. Not only would we have to take some of her judgements to be false, we would also have to take some of them to be in genuine contradiction. This, the argument goes, does not make sense. Instead, we should follow the agent relativist in accepting (JD) and (UE). Firstly, given the close link between actual application and extension guaranteed by (JD) and (UE), semantic misclassifications would be ruled out (under optimal conditions). Secondly, from the agent relativist's point of view, the contradictions that may seem to arise during the course of a series of forcedmarch experiments would be merely apparent, as there would be semantically relevant differences between any apparently contradictory judgements. For instance, on Raffman's view, such judgements are made with respect to different psychological contexts. Just like there is no contradiction between my saying 'I'm hungry' and your saying 'I'm not hungry', there is, on Raffman's view, no genuine contradiction between utterances of ' $x$ is $\mathrm{P}$ ' and ' $x$ is not $\mathrm{P}$ ',

${ }^{20}$ Here, and henceforth, the term 'objectivist' is used as shorthand for 'anti-agent-relativist'.

${ }^{21}$ For instance, see Soames, op. cit., at pp. 213-214; Shapiro, op.cit., at p. 26. 
This is the pre-peer reviewed version of the following article: Akerman, J. 'Forced-march Sorites arguments and linguistic competence', dialectica 67 (2013): 403-426, which bas been published in final form at bttp://dx.doi.org/10.1111/1746-8361.12038. This article may be used for non-commercial purposes in accordance with Wiley Terms and Conditions for Self-Archiving.

where 'P' is a vague predicate and $x$ is a non-clear case of application for ' $\mathrm{P}$ ', as long as these utterances are made with respect to different psychological contexts. ${ }^{22} 23$

A (direct) forced-march argument complemented in this way would not be question begging in the obvious way observed earlier. But of course, its force now depends on whether or not there are any good independent reasons for accepting the claim that the only way to make sense of the forced-march Sorites data is to accept principles like (JD) and (UE). The focus in what follows will be on the idea that considerations about linguistic competence can provide such reasons, and it will be argued that the prospects for this are dim. As already mentioned, the forced-march Sorites data themselves will not be questioned, nor will the claim that objectivists are committed to ascribing classificatory mistakes to the agents in forced-march Sorites scenarios. I do, however, have some reservations concerning the claim that objectivists must ascribe genuine contradictions to the agents. But as this issue will not be our main focus here, I shall leave it to one side for now, and instead address it (albeit briefly) in the concluding remarks below.

\section{Linguistic competence}

The idea that considerations about linguistic competence could be used to argue for agent relativism is far from new. The following passage is from one of Raffman's earliest papers on vagueness, published nearly twenty years ago:

[S]ince our actual applications of vague predicates vary with psychological context, it follows that if the (true) extensions of these predicates do not thus vary, then we are

\footnotetext{
22 This holds mutatis mutandis for Soames's and Shapiro's views as well. It should be pointed out though, that when it comes to so-called non-indexical contextualism, this comparison is not entirely adequate. However, the general point would hold anyway. For further discussion see *******.

${ }^{23}$ As long as we take the utterances to be relative to the relevant agent/time-specific factors, this would be the obvious way to explain away the apparent contradictions. However, if one were to take the utterances to be objective, i.e. as saying something like 'Item \#545 is objectively P' and 'Item \#545 is objectively not P', respectively, the agent relativist may follow Goldstein (op. cit., at p. 64) in saying that the utterances are neither true nor false but nonsensical, since it does not make sense to take 'P' to have objective extensions. In this case, the agent relativist will not be in a position to say that the judgements are correct (true), but given that nonsensical utterances do not genuinely contradict anything, she can still avoid ascribing any genuine contradictions to the agents in the forced march. Thanks to ****** for drawing my attention to this.
} 
This is the pre-peer reviewed version of the following article: Akerman, J. 'Forced-march Sorites arguments and linguistic competence', dialectica 67 (2013): 403-426, which bas been published in final form at bttp://dx.doi.org/10.1111/1746-8361.12038. This article may be used for non-commercial purposes in accordance with Wiley Terms and Conditions for Self-Archiving.

linguistically incompetent in their use. But of course we are not incompetent in the use of these words. ${ }^{24}$

For present purposes, we can grant that actual application varies with psychological contexts. The relevant question is what this tells us about (UE), i.e. whether such variation entails variation in extension. The claim made in this passage is that denying (UE) would lead to the absurd conclusion that ordinary speakers are incompetent in their use of vague language. This claim in turn depends on the (implicit) assumption that in order for a speaker to count as linguistically competent with a vague predicate 'P', her actual applications of 'P' at a time $t$ must not diverge from the extension with which 'P' is used by her at $t$ (i.e. the (true) extension of ' $\mathrm{P}$ ' at $t$ ). So what we have now is, in effect, a forced-march Sorites argument that depends on a certain constraint on linguistic competence.

Before we turn to the discussion of this argument, a few preliminary remarks are in order. Firstly, the constraint on linguistic competence needs to be qualified in the same way as (JD):

(LC) Linguistic competence with a vague predicate 'P' requires that one's actual application of 'P' at $t$ (under optimal conditions) does not diverge from the extension with which one uses 'P' at $t$.

The rationale for the qualification is the same as in the case of (JD); we do not want the constraint to exclude the possibility of mistakes due to unfavourable external conditions, misinformation, or temporary dips in performance level. ${ }^{25}$

Secondly, being a competent speaker of a language containing vague predicates involves a lot of things. So, let us put aside some of those that are not at issue here. One aspect of competence with vague predicates that we can safely put aside is linguistic competence in the Chomskian sense, as defined by the set of rules (the grammar) manifested in the speakers' understanding of

\footnotetext{
${ }^{24}$ Raffman, 'Vagueness without paradox', at p. 66. The argument is repeated in 'Vagueness and context-relativity', at p. 190.

${ }^{25}$ Of course, in order for the argument to work as intended given this qualification of the constraint, we need to assume that the pattern of application would continue to vary across different runs of the forced march, even under optimal conditions, since otherwise there would be no pressure to adopt the agent relativism in order to satisfy the (LC). For present purposes, this assumption will be accepted, even though it may be hard to confirm empirically. It should also be noted that the forced-march argument might work even if we weaken the conditions in (LC), but as that would yield a stronger constraint, I prefer to keep it as it is for present purposes. As my aim here is to question the constraint, I want to consider it in its weakest and most plausible form.
} 
This is the pre-peer reviewed version of the following article: Akerman, J. 'Forced-march Sorites arguments and linguistic competence', dialectica 67 (2013): 403-426, which bas been published in final form at bttp://dx.doi.org/10.1111/1746-8361.12038. This article may be used for non-commercial purposes in accordance with Wiley Terms and Conditions for Self-Archiving.

syntactically acceptable usage. ${ }^{26}$ Clearly, there is nothing about the forcedmarch data that commits an objectivist to deny that ordinary speakers are competent in this sense. Rather, what is at issue is what might be called classificatory competence, in virtue of which ordinary speakers can correctly classify objects as falling, or not falling in the extension of a predicate.

However, there is also an aspect of classificatory competence that we can safely put aside for present purposes, namely classificatory competence with respect to the clear cases at the beginning and end of the Sorites series. It is characteristic of clear cases that, under optimal conditions, competent speakers do not disagree about their semantic status, and their judgements on these are stable over time. Even on an agent relativist view, there will be significant overlaps between different agent/time-relativized extensions of vague predicates, and when it comes to clear cases, the overlap will be complete, at least under optimal conditions. ${ }^{27}$ Consequently, when it comes to clear cases, there will be no variation in application across different runs of the forcedmarch Sorites experiment (under optimal conditions), and thus there will be nothing about the forced-march data that commits an objectivist to deny that ordinary speakers are perfectly classificatorily competent when it comes to clear cases.

The crucial question, then, is if linguistic competence with vague language should be taken to entail perfect classificatory competence (under optimal conditions) with respect to non-clear cases. ${ }^{28}$ If we were to accept (LC) and take it to apply in full generality, we would be committed to a positive answer to this question. However, as shall be argued in what follows, there is scope for denying (LC), at least when it comes to non-clear cases, and, contrary to the line of argument laid out above, the objectivist can make sense of the ascriptions of classificatory mistakes to the agents in the forced march.

Let us start with a few remarks regarding ordinary speakers' epistemic access to the extensions of vague predicates. Everyone can agree that vagueness gives rise to a certain kind of unclarity. ${ }^{29}$ Whether this unclarity is due to ignorance about existing facts of the matter or whether it is due to

\footnotetext{
${ }^{26}$ For instance, see Chomsky, N. Aspects of the Theory of Syntax. Cambridge, Massachusetts, MIT Press (1965), at pp. 3-9.

${ }^{27}$ Cf. Raffman, 'Vagueness without paradox', at p. 67; Goldstein op. cit., at p. 64.

${ }^{28}$ Since, on the agent-relativist view, the extensions are determined subjectively rather than objectively, there will be no objective extension, and no objective fact of the matter to be perfectly correct about. Still, as we have seen, forced-march arguments rest on the claim that competent agents' judgements are perfectly correct relative to the extensions with which they use the predicate on the occasion of the judgement (under optimal conditions).

${ }^{29}$ Several authors have taken this to be a suitable neutral starting point for theorizing about vagueness. See Williamson, op. cit., at p. 2; M. Sainsbury, 'Why the world cannot be vague', Southern Journal of Philosophy 33, pp. 63-81, at p. 64; Keefe, Theories of Vagueness, at p. 6.
} 
This is the pre-peer reviewed version of the following article: Akerman, J. 'Forced-march Sorites arguments and linguistic competence', dialectica 67 (2013): 403-426, which bas been published in final form at bttp://dx.doi.org/10.1111/1746-8361.12038. This article may be used for non-commercial purposes in accordance with Wiley Terms and Conditions for Self-Archiving.

genuine non-epistemic indeterminacy is of course a matter of controversy, but everyone can agree that when it comes to certain items in the middle of the Sorites series for a vague predicate 'P', we do not know what their semantic status is. That is to say, for some $x$, we neither know that $P x$ nor that not-Px. ${ }^{30}$ If there is a fact of the matter here, we are ignorant of it, and if there is no fact of the matter, there is nothing to know, and thus we cannot know it. Moreover, even if our lack of knowledge were a matter of ignorance, it seems that no amount of (non-semantic) information about the subject matter could relieve us from this ignorance. So, no matter how epistemically well placed we are, we will still lack knowledge of the semantic status of some items. ${ }^{31}$ This means that partial lack of semantic knowledge is to be expected even from a competent speaker in optimal conditions.

Given this, it seems that it should not be too difficult for the objectivist to make sense of the idea that ordinary competent speakers could make classificatory mistakes in the forced-march Sorites. Firstly, she can happily accept the forced-march data, and agree that on her view, the agents make certain classificatory mistakes. Secondly, she can point out that as the experiment is set up, the agent is forced to make judgements about things about which she lacks sufficient knowledge. Thus, it makes sense to expect some mistakes on the part of the agent, even if she is a normal competent speaker and the conditions are optimal. Indeed, the objectivist could say that the mistakes are likely to occur because the agent is forced to make judgements about things of which she lacks knowledge.

Agent relativists will have to tell a rather different story, but there is no reason to think that they will deny the idea that there are items $x$ such that we ordinary competent speakers neither know that $P x$ nor know that not-Px. For instance, recall that on Raffman's view, there is no time $t$ at which the agent knows the semantic status of every item in the series at $t$, and this would arguably remain the case even under optimal conditions. That is to say, even normal competent speakers with access to all relevant non-semantic facts concerning the objects in the Sorites series should be expected to lack some semantic knowledge. That the extensions are "subjectively" determined does not mean that the speakers have full epistemic access to them.

Moreover, from an agent relativist point of view, it seems that this ideathat for some $x$, the agent knows neither that $P x$ nor that not-Px-is perfectly consistent with the idea that we should expect all the agent's judgementswhich are of the form $P x$ or not-Px- to come out as semantically correct.

${ }^{30}$ Cf. P. Greenough, 'Vagueness: a minimal theory', Mind 112 (446), pp. 235-281, at p. 257.

31 It would not help to introduce a 'borderline' semantic status, as there would still be some items whose status remained unclear. For instance, an object may be neither clearly P nor clearly borderline P. 
This is the pre-peer reviewed version of the following article: Akerman, J. 'Forced-march Sorites arguments and linguistic competence', dialectica 67 (2013): 403-426, which bas been published in final form at bttp://dx.doi.org/10.1111/1746-8361.12038. This article may be used for non-commercial purposes in accordance with Wiley Terms and Conditions for Self-Archiving.

Firstly, in order to be reliable in one's classifications in the forced-march, one need not at each point know the semantic status of each item in the series. It suffices that one knows the semantic status of each object at the moment when one's judgement on it is passed. Of course, in view of the above considerations about unclarity, it may be doubted that such knowledge can appropriately be ascribed to the agent. But, secondly, classificatory reliability does not even require that one has propositional knowledge of the content of one's current judgements, or even a confident belief in these contents. Neither lack of knowledge of nor lack of confidence (due to unclarity) in propositions of the form ' $x$ is $\mathrm{P}$ ' and ' $x$ is not $\mathrm{P}$ ' excludes that the agent can reliably get all of her judgements right, since this is perfectly compatible with her having an ability to make semantically correct classifications. Agent relativists could make sense of such an ability in terms of (JD), and in general, there is nothing mysterious about the combination of such abilities and ignorance of the kinds described above. To take an example that should be familiar to most of us, one may have the ability to find and maintain the equilibrium required in order not to fall off one's bicycle without ever being able to specify where one's point of gravity must be located in order to reach and maintain this equilibrium. This is an ability that one has in virtue of being a competent bicyclist. By analogy, the agent relativist can simply say that the ability to classify the non-clear items correctly in the forced-march experiment is an ability that the agents have in virtue of being competent speakers. ${ }^{32}$ Even when it is unclear to them which side of the boundary they are on, as it were, they are able to get the judgement (semantically) right.

What, then, does this tell us about the dialectical situation between these theories? Well, even if both of the stories are coherent, neither of them, taken on its own, constitutes an argument against the opposing view. In particular, the agent relativist story does not in itself give us any independent reason for accepting (LC) or (JD), it merely shows how these different aspects of the view cohere. Thus, the question remains whether or not there is any (independent) reason for thinking that an ability of the kind appealed to in the agent-relativist story is essential to competence with vague predicates of the kind that we should expect from ordinary speakers. Absent such a reason, it is hard to see how (LC) could be invoked in order to clinch the above forced-march Sorites argument.

32 At a first glance, it may seem odd to take this kind of ability to be an aspect of competence. However, we can make sense of this if we leave room for a "minimalist" notion of competence according to which the question of competence is not distinct from the question of how the relevant facts determine meaning and extension. Cf. A. Wikforss, 'Are there understanding-assent links?', The Baltic International Yearbook of Cognition, Logic and Communication, Volume 5: Meaning, Understanding and Knowledge (2010), pp. 1-17, at p. 3. 
This is the pre-peer reviewed version of the following article: Akerman, J. 'Forced-march Sorites arguments and linguistic competence', dialectica 67 (2013): 403-426, which bas been published in final form at bttp://dx.doi.org/10.1111/1746-8361.12038. This article may be used for non-commercial purposes in accordance with Wiley Terms and Conditions for Self-Archiving.

Can the analogy in the above story be of any help in providing such reasons? In the bicycle case, it seems clear that one would not count as competent unless one had the ability to find and maintain the required equilibrium under favourable conditions. After all, learning to ride a bicycle includes learning how to balance on it, so this is something we should expect from any competent bicyclist. But an analogous argument concerning linguistic competence and the ability to correctly classify non-clear items in the forcedmarch experiment does not seem very compelling. Learning a vague language does not (typically) involve learning how to make semantically correct classifications of non-clear cases. The typical way in which one comes to understand a vague predicate is quite different, as Soames points out in the following passage:

Often we are shown clear and unproblematic examples of its application and nonapplication. [...] From these instructions, we learn both how to characterize the particular examples shown to us and how to generalize the use of the predicate to characterize many items outside the original sample. For example, in coming to understand the predicate bald, we learn that whether or not people are bald depends on how much hair they have on their heads. People with little or no hair-no more than the bald individuals in our original sample — are bald. People with a lot of hair-at least as much as the "not bald" individuals in the original sample-are not bald. ${ }^{33}$

By being shown certain clear cases, we learn what properties are relevant for the application of the predicate, so knowing this is clearly something that we should expect from any competent speaker. Moreover, in learning how to generalize from the clear cases of application and non-application, the speaker will acquire (implicit) knowledge of so called penumbral connections, such as 'Any man who is balder than a bald man is also bald'. ${ }^{34}$ Now, these are aspects of learning and competence that objectivists and agent relativists can agree about. But what about the ability to make semantically correct classifications of non-clear cases in the forced-march experiment (under optimal conditions)? Although there may not be anything incoherent about taking competent speakers to have an ability of this kind, we still have not seen any independent

33 Soames, op. cit., at pp. 209-210.

34 The term 'penumbral connection' is due to Kit Fine, 'Vagueness, truth, and logic', Synthese 30 (1975), pp. 265-300. 
This is the pre-peer reviewed version of the following article: Akerman, J. 'Forced-march Sorites arguments and linguistic competence', dialectica 67 (2013): 403-426, which bas been published in final form at bttp://dx.doi.org/10.1111/1746-8361.12038. This article may be used for non-commercial purposes in accordance with Wiley Terms and Conditions for Self-Archiving.

motivation for doing so, and it is not easy to see what aspect of our linguistic education could plausibly be the source of such an ability.

Perhaps it could be claimed that in learning vague predicates, we learn to follow our judgemental dispositions, and this would, on the agent-relativist picture, be tantamount to learning how to make semantically correct classifications of non-clear cases. But, just like the above story, this merely shows how agent relativists might make sense of how we acquire this kind of ability in the process of learning vague language. Such an account would be of no help when it comes to arguing for agent relativism, since it presupposes a close link between judgements and extensions of the very kind that is under dispute. What is still missing in order to make the argument work is an independent reason for accepting (LC).

It may fairly be pointed out that the simple picture sketched above is incomplete in that it leaves out important aspects of learning to use vague language in various everyday situations in order to achieve certain practical goals. It seems plausible to assume that ordinary speakers will typically acquire abilities of this kind in the process of becoming competent language users, and it seems rather clear that we expect ordinary competent speakers to have such abilities. One thing that is of particular interest for present purposes is the fact that competent speakers of vague language often manage to apply vague predicates to non-clear cases in ways that seem perfectly appropriate given the situation at hand. Consider the following example:

There are two pigs in a pen: the first a runt, the second quite round but not really fat. Now the farmer says, "The fat pig won a prize." His neighbor could protest that neither pig is really fat. But he does not protest. He understands that the rounder is meant, and both of them know it. ${ }^{35}$

The farmer's (indirect) classification of the rounder pig as fat seems perfectly appropriate given the situation and his practical goals. Moreover, this is a completely ordinary everyday situation, which we should expect any competent user of vague language to be able to handle. Nothing beyond the competence that we expect from normal speakers of English seems to be required, either from the farmer or from his neighbour.

\footnotetext{
35 A. Kyburg and M. Morreau, 'Fitting words: vague language in context', Linguistics and Philosophy 23 (2000), pp. 577-597, at p. 577. For an empirical study and discussion of this phenomenon, see K. Syrett, C. Kennedy and J. Lidz, 'Meaning and Context in Children's Understanding of Gradable Adjectives', Journal of Semantics 27 (2009), pp. 1-35.
} 
This is the pre-peer reviewed version of the following article: Akerman, J. 'Forced-march Sorites arguments and linguistic competence', dialectica 67 (2013): 403-426, which bas been published in final form at bttp://dx.doi.org/10.1111/1746-8361.12038. This article may be used for non-commercial purposes in accordance with Wiley Terms and Conditions for Self-Archiving.

Let us consider another example, adapted from Mark Sainsbury. ${ }^{36}$ In a paint shop, there are two shelves, marked 'Red' and 'Orange', respectively, and a set of cans, ranging from (clearly) red to (clearly) orange. The shop assistant has been given the task of arranging these cans on the two shelves in an appropriate way. The task turns out to be more difficult than expected, as the cans form a Sorites series from red to orange. Fortunately, they are numbered according to the relative redness/orangeness of the paint they contain. This makes it easy to avoid putting a can on the 'Red' shelf that is less red than some can on the 'Orange' shelf. In other words, the assistant can quite easily avoid violating any penumbral connections in his classification of the cans. But in order to fulfil his task, he will have to classify some non-clear cases as falling in one of the two available categories, and, in this sense, he will have to draw a boundary in the series. Thus, the assistant finds himself in a situation that resembles a forced-march experiment in several respects. ${ }^{37}$ Nevertheless, given that he is a competent speaker, we would typically expect him to handle this situation without too much trouble.

If this is right, then, it seems that ordinary speakers' competence with vague predicates comprises an ability to handle various situations in which one needs to make classifications of non-clear cases, including cases which are similar to the forced-march Sorites. Now, it may be thought that in the light of this, we should not expect ordinary speakers to have any particular trouble in handling the forced-march Sorites either.

In one sense, I think that this is precisely right, but the sense in which it is right is not the one that would be needed in order to provide us with a good reason for accepting (LC). What we have good reasons to ascribe to normal competent speakers is an ability to apply vague predicates to non-clear cases in order to fulfil certain practical purposes, and to understand other speakers when they do the same thing. ${ }^{38}$ In particular, we should expect normal competent speakers to be able to communicate efficiently with vague language, and this will sometimes require classification of non-clear cases. Clearly, this does not mean that we should expect these classifications to be semantically

\footnotetext{
${ }^{36}$ M. Sainsbury, 'Concepts without boundaries' in R. Keefe \& Peter Smith (eds.) Vagueness: $A$ reader, Cambridge, MIT Press (1997), pp. 251-264, at pp. 259-260.

${ }^{37}$ See Shapiro (op. cit., at p. 22) and ****** for further discussion of these similarities.

${ }^{38}$ Following David Lewis ('Scorekeeping in a language game', Journal of Philosophical Logic 8 (1979), pp. 339-359), we can account for this in terms of (pragmatic) accommodation: sometimes we are willing to accept (without qualification) sentences that are not clearly (or determinately) true given that they are true enough in the situation at hand. On Lewis's view, accommodation does not mean that the extension with which the predicate is used changes as a function of what is true enough or what the speaker and her interlocutors accept in different situations. The appropriate application of the predicate to non-clear cases in a certain situation is up for negotiation among competent language users, but the extension is not.
} 
This is the pre-peer reviewed version of the following article: Akerman, J. 'Forced-march Sorites arguments and linguistic competence', dialectica 67 (2013): 403-426, which bas been published in final form at bttp://dx.doi.org/10.1111/1746-8361.12038. This article may be used for non-commercial purposes in accordance with Wiley Terms and Conditions for Self-Archiving.

correct, as we can communicate efficiently by saying things that are not really true (and by using descriptions that do not really fit the objects about which we want to communicate something). Thus, although we do have reasons to expect ordinary competent speakers to be able to apply vague predicates to non-clear cases in a way that is appropriate in order to achieve certain practical (e.g. communicative) purposes, we do not thereby have any reason to expect them to be able to make semantically correct applications of non-clear cases in the forced march Sorites.

Agent relativists sometimes emphasize that there does not seem to be anything wrong about the way in which the agent applies vague predicates in the forced march. ${ }^{39}$ Again, I think that this is right in one sense, but not in a sense that would help with respect to the argument we are concerned with here. The sense in which it is right is that the agent's judgements are perfectly appropriate given the situation she finds herself in. As explained above, the way that competent speakers handle the forced march and similar situations will typically be perfectly in order from a pragmatic point of view, and there will typically not be anything inappropriate about the way they apply vague predicates in these situations, but the classifications need not be semantically correct in order to be appropriate. The impression that it seems out of place to accuse the agent in the forced-march Sorites experiment of having done anything wrong may be explained in terms of appropriateness rather than truth, and thus this observation does not provide any independent reason for accepting the assumptions on which the forced-march argument rests.

Indeed, the impression that the agent's judgements are appropriate appears to remain even under the assumption that some of the applications are semantically incorrect. Suppose that it was somehow discovered that the agent had made some false judgements concerning items in the middle of the series (despite the conditions being optimal). It would still seem just as odd to accuse her of having done something inappropriate. After all, she has just done what she had to do given the rules of the game, as it were, so in that sense, she did not do anything wrong. ${ }^{40}$ But not doing anything wrong (in one sense) is of course compatible with being wrong (in some other sense).

An analogy borrowed from Rosanna Keefe may be helpful here. ${ }^{41}$ The forced-march experiment resembles somewhat a situation in which one is trying to guess the weight of something, e.g. a giant pumpkin at a farmers market, in order to win a prize, e.g. the pumpkin in question. In guessing, one will try to get as close as possible, but there will be nothing inappropriate about

${ }^{39}$ For instance, see Shapiro, op. cit., at p. 26.

${ }^{40}$ Cf. Shapiro, op. cit., at p. 26.

${ }^{41}$ R. Keefe, 'Context, vagueness, and the sorites: Comments on Shapiro', in Jc Beall (ed.) Liars and Heaps, New York, Oxford University Press (2003), pp. 73-83, at p. 79. 
This is the pre-peer reviewed version of the following article: Akerman, J. 'Forced-march Sorites arguments and linguistic competence', dialectica 67 (2013): 403-426, which bas been published in final form at bttp://dx.doi.org/10.1111/1746-8361.12038. This article may be used for non-commercial purposes in accordance with Wiley Terms and Conditions for Self-Archiving.

saying 'It weighs 453 pounds' although it neither does weigh exactly that, nor does one really believe that it does. In order to enter the contest, one has to say something, but it should not be taken as a genuine assertion expressing a belief about the exact weight of the pumpkin. Thus, just like in the scenario described above, it would seem completely out of place to accuse someone of having done something inappropriate in guessing the wrong weight. But of course, that does not change the fact that the guess was wrong. ${ }^{42}$

We have seen that we should expect ordinary speakers to be able to classify clear cases in a semantically correct way (at least under optimal conditions), to have (implicit) knowledge of penumbral constraints, and to have a pragmatic competence in virtue of which they can make use of vague language in order to achieve their everyday (communicative) purposes. These all seem to be central aspects of ordinary competent use of vague language, but I do not want to claim that this list is exhaustive. For instance, perhaps we should also expect competent speakers to take vague predicates to be (in some sense) tolerant to sufficiently small changes along the relevant dimension of comparison, or to consider certain disagreements concerning non-clear cases to be legitimate. ${ }^{43}$ However, from a neutral point of view, there seems to be no reason to take ordinary competence with vague predicates to require an ability to classify nonclear cases in a semantically correct way, not even under optimal conditions. The upshot of this is that we should at the very least leave the possibility open that linguistic competence with vague predicates be compatible with error concerning non-clear cases, even under optimal conditions. ${ }^{44}$ If this is right, then, objectivists can quite appropriately deny principles like (LC), and thus resist forced-march Sorites arguments that rely on such principles.

\section{Concluding remarks on use, extensions and contradictions}

It seems plausible to take the extensions of vague predicates to be determined, in some way, by how they are used by competent speakers. Given this, the fact that agent relativism posits a very close and direct relation between (individual)

\footnotetext{
${ }^{42}$ Cf. Keefe, 'Context, vagueness, and the sorites', at p. 80.

${ }^{43}$ For instance, see M. Eklund, 'What vagueness consists in', Philosophical Studies 125 (2005), pp. 27-60, at p. 41, and Goldstein, op. cit., at p. 63. The notion of tolerance was introduced by Crispin Wright, 'On the coherence of vague predicates', Synthese 30 (1975), pp. 325-365, at pp. 333-334. See ****** for examples and discussion of different versions of tolerance.

${ }^{44} \mathrm{I}$ am not the first to endorse a claim of this kind, but so far, neither critics nor defenders of agent relativism have gone into sufficient detail about how such claims should be understood and evaluated in relation to the forced-march Sorites argument. See Keefe, 'Context, vagueness, and the sorites', at p. 79.
} 
This is the pre-peer reviewed version of the following article: Akerman, J. 'Forced-march Sorites arguments and linguistic competence', dialectica 67 (2013): 403-426, which bas been published in final form at bttp://dx.doi.org/10.1111/1746-8361.12038. This article may be used for non-commercial purposes in accordance with Wiley Terms and Conditions for Self-Archiving.

judgements and extensions may seem to count strongly in its favour. However, adopting principles like (JD) and (UE) is not the only way to accommodate the idea that competent use determines the extensions of vague predicates. To be sure, the agent relativist account is neat and simple, but that is not enough to give us good reasons to accept it. Firstly, we should ask ourselves whether we have any reason to think that the actual relationship really is as simple as this account suggests. If not, it may be regarded as simplistic rather than simple. ${ }^{45}$ Secondly, even if we want to acknowledge the importance of competent speakers' judgements, agent-relativist accounts like Raffman's may be taken to be too individualistic. Why should we relativize extensions to individual speakers (or even small groups of conversationalists) rather than, say, letting the extensions be determined by the totality of the judgemental dispositions of the relevant linguistic community? One might, for instance, prefer a collectivist view, according to which for any vague predicate 'P', an object's being $\mathrm{P}$ depends on its propensity to be judged to be $\mathrm{P}$ by all (or at least a high preponderance of) competent agents (under optimal conditions). ${ }^{46}$

One may object that since that ordinary competent speakers' judgemental dispositions are in conflict and in flux, even under optimal conditions, it is hard to see how the determination of extensions is supposed to work on any such collectivist view. ${ }^{47}$ Given the assumption that the extensions must be fixed and sharply bounded, this point is well taken, but the objection appears to lose much of its force if this assumption is dropped. And this assumption can indeed be dropped. A denial of (individualistic) agent relativism in favour of a collectivist view is compatible with the claim that the extensions are neither sharply bounded nor fixed, since the function from collective use to extension may either be determinate or indeterminate, and certain variations in the overall use or dispositions may cause the extension to change over time. In sum, the general and plausible claim that the extensions of vague predicates are determined (in some way) by how they are used by competent speakers is, at least prima facie, compatible with theories of vagueness of very different kinds, and it is far from clear that (individualistic) agent-relativist views are better suited to accommodate it than their rivals. ${ }^{48}$

The discussion so far has focused on classificatory competence. As promised above, I will now turn to some brief remarks about how objectivists might handle the apparent contradictions in the forced march. One option would be to draw on Keefe's analogy with guessing, and deny that the

${ }^{45}$ Cf. Keefe, 'Context, vagueness, and the sorites', at pp. 78-79.

46 Thanks to ***** for helpful comments on this.

47 This objection was raised by $* * * * * *$.

${ }^{48}$ Cf. Williamson op. cit., at pp. 205-212, and Keefe, Theories of V agueness, at pp. 79-83; 'Context, vagueness, and the sorites', at p. 78. 
This is the pre-peer reviewed version of the following article: Akerman, J. 'Forced-march Sorites arguments and linguistic competence', dialectica 67 (2013): 403-426, which bas been published in final form at bttp://dx.doi.org/10.1111/1746-8361.12038. This article may be used for non-commercial purposes in accordance with Wiley Terms and Conditions for Self-Archiving.

judgements about non-clear cases in the forced march are genuine assertions. The semantic contents of these judgements may still be in contradiction, but since neither of them is uttered with genuine assertoric force, there is a sense in which the agent has not genuinely contradicted herself; she has not asserted two contradictory propositions. ${ }^{49}$

Another option would be to emphasize (again) that due to the unclarity that comes with vagueness, the semantic status of non-clear cases is not something that ordinary speakers can be expected to be very confident about. In view of this, we should not expect judgements on such cases to be very stable, and thus, it is not very surprising that the agent in the forced march tend to judge some non-clear cases differently across different runs through the Sorites series. Now, if we were to take the extension to remain fixed across these different runs it would be hard to deny that these judgements genuinely contradict each other. ${ }^{50}$ However, we would not thereby have to take the agents to be committed to any genuine contradictions. Instead, it could be claimed that the reason that the agents in the forced-march Sorites experiments tend to make different judgements on different runs is simply that they tend to change their minds concerning the non-clear cases across the different runs. ${ }^{51}$ As an agent changes her mind about a non-clear case, and passes a new judgement on it, she thereby implicitly retracts her previous judgement. ${ }^{52}$ This means that a theory may entail that the forced-march Sorites data include

${ }^{49}$ Of course, since this solution does not appeal to semantic differences, the sense in which the apparent contradiction is not genuine is not the same as on the agent-relativist account described above.

${ }^{50}$ After all, the judgements are about one and the same object $x$, they have the form ' $x$ is P' and ' $x$ is not P', respectively, and 'P' expresses the same property and has the same extension in the two situations in which the judgement is made.

51 The objectivist could even invoke something like Raffman's account of the psychological mechanisms behind the judgements in order to explain why the pattern of application shifts in the way that it does, as long as she denies that these mechanisms also determine the extensions. See $* * * * * *$ and $* * * * * *$ for further discussion.

${ }^{52}$ In order to model how this works, one may invoke something similar to the notion of a conversational scoreboard that Shapiro borrows from David Lewis. (See Lewis, op. cit; Shapiro, op. cit., at p. 12.) Among other things, such a scoreboard contains, at any time $t$, all the propositions that the speaker-and her interlocutors, if there are any-are committed to at $t$. When a proposition is asserted, it goes on the score (provided that none of the interlocutors protests). What happens to the score if the agent in the forced-march experiment denies something about a non-clear case that she has previously asserted is simply that the previous judgements is eliminated from the conversational scoreboard as the new judgement is added. In fact, this is just what happens on Shapiro's view. Now, in accordance with his agentrelativist view, he also takes such shifts to entail shifts in the extension of the vague predicate, and this is something that an objectivist must deny. But this does not mean that Shapiro's notion of a conversational score cannot be invoked on the pragmatic level, as it were, in order to model changes in the agent's commitments. 
This is the pre-peer reviewed version of the following article: Akerman, J. 'Forced-march Sorites arguments and linguistic competence', dialectica 67 (2013): 403-426, which bas been published in final form at bttp://dx.doi.org/10.1111/1746-8361.12038. This article may be used for non-commercial purposes in accordance with Wiley Terms and Conditions for Self-Archiving.

judgements that genuinely contradict each other, without thereby entailing that the agents' behaviour in the forced-march Sorites commit them to any genuine contradictions.

As a final remark, it may be noted that since the purpose here has been to discuss forced-march arguments, the scope has been limited to forced-march Sorites data, which concern simple judgements of the form ' $x$ is (not) P'. Recently, there has been some discussion concerning data of other kinds, including results from empirical studies indicating that ordinary competent speakers are quite willing to accept statements of the form ' $x$ is $\mathrm{P}$ and $x$ is not $\mathrm{P}$ ' (i.e. outright contradictions) when 'P' is a vague predicate and $x$ is a nonclear case. ${ }^{53}$ This raises many interesting issues, including questions concerning how these data should be interpreted, and how they could be brought to bear on issues like the ones discussed above. But these are topics for another day.

${ }^{53}$ D. Ripley, 'Contradiction at the borders', in R. Nouwen, R. van Rooij, U. Sauerland \& H-C. Schmitz (eds.), Vagueness in Communication, Berlin Heidelberg, Springer-Verlag (2011), pp. 169188; S. Alaxtib \& F.J. Pelletier, 'The Psychology of Vagueness: Borderline Cases and Contradictions', Mind and Language 26 (2011), pp. 287-326; P. Cobreros, P. Egré, D. Ripley \& R. Van Rooij, 'Tolerant, classical, strict', Journal of Philosophical Logic 41 (2012), pp. 347-385; S. Alxatib, P. Pagin \& U. Sauerland, 'Acceptable contradictions: pragmatics or semantics? A reply to Cobreros et al.', Journal of Philosophical Logic (forthcoming). 